work to predict successfully the breakdown strength of silicon dioxide.

With this exception, it must be said that for a research student or working scientist who wishes to be quickly and smoothly introduced to or updated with respect to the concepts of transport in insulators (ionic as well as electronic), it will be well worth his while to have this book on his shelf. A lot of effort has been expended in whittling down the arguments to their core and selecting the best experimental examples for the reader's inspection. If the reader then has to go on a bit further in order to make his own value judgments, he will still have saved himself a lot of time in the library. A. G. Holmes-Siedle

\section{Fermi surfaces}

The Fermi Surface : Its Concept, Determination, and Use in the Physics of Metals. By A. P. Cracknell and K. C. Wong. Pp. xii +565 . (Clarendon: Oxford; Oxford University: London, August 1973.) £15.

IN his original work in 1926 Fermi introduced the thermodynamic potential, or degeneracy temperature-what we now call Fermi level-of a gas of electrons. Though he was well aware that these ideas were relevant to electrons in metals, he could hardly have foreseen what central role this concept would assume in solid-state physics and particularly in the theory of metals. As the preface to this book reminds us, Professor Mackintosh thinks that the most appropriate definition of a metal is "a solid with a Fermi surface", the surface being the locus of points in momentum space at which the oneelectron energy is equal to the Fermi level. This quantum concept, in conjunction with the consequences of crystal periodicity, provides the foundation on which the properties of metals can best be discussed. The beautiful, and sometimes bizarre, shapes of these surfaces (the monster, the coronet, the super-egg ...) are natural examples of abstract art, almost reflecting unconscious archetypal models.

The work which has led to the determination of these surfaces is among the most ingenious, elegant and fascinating in modern physics and this book aims at giving a complete authoritative account of all its aspects. It is a combination of an introductory treatise and an extended review article. The first two chapters give those parts of band theory which are necessary for a proper understanding of both theoretical and experimental methods. Chapter 3 describes the experimental methods, then two chapters, bringing up to date the well known review articles by one of the authors, describe the Fermi surfaces of metallic elements. Chapter 6 des. cribes in an elementary way the effect on Fermi surfaces of electron interactions, and the work ends with an admittedly perfunctory treatment of alloys.

Probably the most striking characteristic of this exposition is its extreme clarity. The treatment of even difficult points flows effortlessly and should be well within the grasp of graduates who know the fundamentals of solid-state physics and of quantum theory (old style-the Dirac notation is not used). Of course the task of giving a simplified treatment which is not partly misleading is an impossible one, but we come near to achieving it here, and many teachers will get valuable hints for their lectures. By and large the choice of material appears very sensible; all the necessary definitions and explanations are given (or almost all: for instance the definition of Clebsch-Gordan coefficients seems to be missing); the usual "it can be proved that" is always coupled to an appropriate reference. Some sections are perhaps unduly discursive and some elementary items are included which could have been assumed to form part of the background, for example, Einstein's and Debye's theories of lattice specific heats. A notable omission is any reference to liquid metals. At least the extent of blurring of the Fermi surface might have been indicated, and a reference to Professor March's monograph given.

The book is thus a very useful introduction to the subject, but its main value is as a collection of results of work on Fermi surfaces complete up to 1971 with some later references. The total number of references is almost one thousand and they all fit neatly into their appropriate slot. I have failed to find any aspect of any importance which is not adequately covered. The authors will receive the heartfelt gratitude of all "Fermiologists" and it is safe to say that this will remain the standard treatise on Fermi surfaces for a long time, even if some parts should become surpassed. It is a pity that the price should be so high, even taking into account today's wild inflation, and the quality of reproduction of the illustrations is not outstanding.

\section{Pincherle}

\section{Gas theory}

Mathematical Theory of Transport Processes in Gases. By J. G. Ferziger and H. G. Kaper. Pp. xiii +579 . (NorthHolland: Amsterdam and London, 1972.) Dfl. 120; $\$ 35.25$.

THE year 1972 was the hundredth anniversary of the publication of the Boltzmann equation-apparently an auspicious year for the publication of a book on the kinetic theory of gases as based on this famous equation. This theory gives a complete prescription for calcu- lating transport properties of dilute gases from knowledge of the intermolecular forces. As such, it is one of the most elegant and highly-developed physical theories available. But any book published in 1972 must face a severe testcomparison with two well known monographs, The Mathematical Theory of Non-Uniform Gases by Chapman and Cowling, now in its third edition (1970), and Molecular Theory of Gases and Liquids by Hirschfelder, Curtiss and Bird, in its second printing (1964). These are rightly regarded as classics, and have set a standard by which all other books in the field are measured. Ferziger and Kaper have attempted the difficult task of combining the best features of both of these works in a textbook for graduate study. Let me quote their own words for the reasons for the attempt. Chapman and Cowling ". . . is rather difficult as a text and does not emphasise the calculation of transport properties sufficiently. ... Hirschfelder, Curtiss and Bird, while very good in discussing the calculation of transport properties, compresses the theory far more than desirable".

In my opinion the authors have succeeded admirably in their aim. There is no doubt that a real need exists for such a book, as evidenced by a prevailing opinion to the effect that ". . . reading Chapman and Cowling is like chewing on broken glass; reading Hirschfelder, Curtiss, and Bird is like punching a feather pillow". I wish a book like this had existed when I first started to try to understand kinetic theory.

This book covers much the same ground as Chapman and Cowling, but with more emphasis on intermolecular forces and the computation of transport coefficients. There are also excursions beyond the range of the Boltzmann equation to include modern work on dense gas theory and some discussion of rarefied gas dynamics. A book like this cannot hope to be complete, and in some areas will become out of date very quickly. One can see some signs of this already happening, but I do not feel that this detracts appreciably from the book's value. The discussion of fundamentals and mathematical developments is so well done as to be of almost permanent value, and the treatments of the more rapidly changing areas will enable the reader to proceed for himself into the research literature.

Finally, it is interesting to note that the book developed from a course intended for aeronautical, mechanical and chemical engineers. It should be of equal value to physicists and chemists, and even to biologists interested in phenomena describable by Boltzmann-type equations. I predict that it will be a standard text for some time to come. $\quad$ E. A. Mason 